\title{
Commentary: Association of Breast Milk Fatty Acids With Allergic Disease Outcomes-A Systematic Review
}

\author{
Chad A. Logan ${ }^{1}$ and Jon Genuneit ${ }^{1,2 *}$ \\ 'Institute of Epidemiology and Medical Biometry, UIm University, Ulm, Germany, ${ }^{2}$ 'In-FLAME' the International Inflammation \\ Network, World Universities Network (WUN), Ulm, Germany
}

Keywords: human milk, fatty acids, wheeze, asthma, allergic diseases

A commentary on

OPEN ACCESS

Edited by:

Daniel Munblit,

I.M. Sechenov First Moscow State

Medical University, Russia

Reviewed by:

Wilfried Joachim

Juergen Karmaus,

University of Memphis,

United States

Maria Carmen Collado,

Instituto de Agroquímica y

Tecnología de Alimentos

(CSIC), Spain

${ }^{*}$ Correspondence:

Jon Genuneit

jon.genuneit@uni-ulm.de

Specialty section:

This article was submitted to

Pediatric Immunology,

a section of the journal

Frontiers in Pediatrics

Received: 30 January 2018

Accepted: 23 March 2018

Published: 09 April 2018

Citation:

Logan CA and Genuneit J (2018) Commentary: Association of Breast

Milk Fatty Acids With Allergic

Disease Outcomes -

A Systematic Review.

Front. Pediatr. 6:94.

doi: 10.3389/fped.2018.00094
Association of Breast Milk Fatty Acids With Allergic Disease Outcomes-A Systematic Review by Waidyatillake NT, Dharmage SC, Allen KJ, Lodge CJ, Simpson JA, Bowatte G, et al. Allergy (2018) 73:295-312. doi: 10.1111/all.13300

We were pleased to read the systematic review of studies investigating associations between breast milk fatty acids and allergic disease outcomes by Waidyatillake et al. (1). A comprehensive overview of systematic reviews in allergy epidemiology (2) up to 2014 has identified several systematic reviews on the association of fatty acid intake with allergic disease risk (3-8). We are aware of two further systematic reviews on this topic published in $2015(9,10)$. While these previous reviews have largely synthesized evidence on fatty acid supplementation, also during lactation, only one of them has explicitly synthesized studies ascertaining evidence on breast milk fatty acid levels-but only for asthma as an outcome (8). We thus hope that this systematic review by Waidyatillake et al. will help to spur interest on this potentially important topic.

We have published an original study (11) after the search period of the most recent systematic review which offers additional insight and may thus provide further guidance for future investigations. In our study (11), we investigated associations between breast milk fatty acid composition and several wheeze phenotypes as well as asthma diagnosis up to age 13 years. Here, we addressed several limitations implicated by Waidyatillake et al. (1) as cause for further study (i.e., large sample size, analysis of diverse outcomes, comprehensive statistical analysis, and adjustment for multiple potential covariates or confounders but not for potential mediators). We also improved upon previous studies by employing statistical methodology to account for constant-sum constraint (11), a potentially serious issue when analyzing concentration data $(12,13)$.

As in the majority of the studies reviewed by Waidyatillake et al. (1), we identified no convincing evidence of association between fatty acid composition and childhood respiratory outcomes (11). Furthermore, we showed that previously reported significant associations for omega-3 and omega- 6 fatty acids may have been overstated due to spurious correlation between fatty acids which was not accounted for (11). Yet despite our null findings, we also do not believe that this is the end of the story. Further study of breast milk fatty acids may shed light on potentially more complex relationships between breastfeeding and disease.

Since our results diverge from previous studies likely due to different statistical methodology, we believe a good first step could be to re-examine existing data using simple statistical methodology similar to our own (11). As the sum concentration of all fatty acids within any breast milk sample is bound at $100 \%$ of total fat weight, known as the constant-sum constraint, analysis of raw data 
may often result in spurious correlations $(12,13)$. Interestingly, though these analytical methods for compositional data analysis have been used extensively in investigations of bovine milk (14), few previous studies of human breast milk constituents have truly accounted for compositionality (15). Results from appropriate reanalyses of existing data would serve to test the validity of previous findings. Moreover, they could be used to identify correlations between fatty acid constituents which may be more meaningful to infant and childhood health and disease outcomes than total fat proportions of single fatty acids or fatty acids grouped based on chemical similarities (like grouping all omega-3 fatty acids). Importantly, we show that associations may be attenuated toward the null if negatively correlated (or non-correlated) fatty acids are grouped and analyzed as such (11).

In addition, breastfed children often constitute their own specific subgroup who may be more likely to have healthier and more educated mothers than children who were never breastfed or were breastfed for only a short period of time (16). To overcome this potential selection bias, it may be important to investigate those children not receiving breast milk alone or at all. In early infancy, before introduction of solids, infant formula will be their source of nutrition. Thus, future studies could embark on the strategy of investigating the association of fatty acid profiles of both breast milk and infant formulas forming the diet of an unselected study population with allergic outcomes.

Furthermore, fatty acid concentrations in breast milk have been shown to vary over the course of lactation (17). Infant formula may provide a more stable fatty acid profile which may allow researchers to identify associations which are difficult to observe in breast milk. Following the idea that the source of fatty acids could be extended from pure breast milk to formula,

\section{REFERENCES}

1. Waidyatillake NT, Dharmage SC, Allen KJ, Lodge CJ, Simpson JA, Bowatte $\mathrm{G}$, et al. Association of breast milk fatty acids with allergic disease outcomes-a systematic review. Allergy (2018) 73:295-312. doi:10.1111/ all. 13300

2. Genuneit J, Seibold AM, Apfelbacher CJ, Konstantinou GN, Koplin JJ, La Grutta S, et al. Task force 'overview of systematic reviews in allergy epidemiology (OSRAE)' of the EAACI Interest Group on Epidemiology. Overview of systematic reviews in allergy epidemiology. Allergy (2017) 72:849-56. doi:10.1111/all.13123

3. Ruxton CHS, Reed SC, Simpson MJA, Millington KJ. The health benefits of omega-3 polyunsaturated fatty acids: a review of the evidence. J Hum Nutr Diet (2004) 17:449-59. doi:10.1111/j.1365-277X.2004.00552.x

4. Sausenthaler S, Koletzko B, Heinrich J. Dietary fat intake and allergic diseases. Curr Nutr Food Sci (2006) 2:351-9. doi:10.2174/157340106778699395

5. Anandan C, Nurmatov U, Sheikh A. Omega 3 and 6 oils for primary prevention of allergic disease: systematic review and meta-analysis. Allergy (2009) 64:840-8. doi:10.1111/j.1398-9995.2009.02042.x

6. Kremmyda L-S, Vlachava M, Noakes PS, Diaper ND, Miles EA, Calder PC. Atopy risk in infants and children in relation to early exposure to fish, oily fish, or long-chain omega-3 fatty acids: a systematic review. Clin Rev Allergy Immunol (2011) 41:36-66. doi:10.1007/s12016-009-8186-2

7. Saadeh D, Salameh P, Baldi I, Raherison C. Diet and allergic diseases among population aged 0 to 18 years: myth or reality? Nutrients (2013) 5:3399-423. doi:10.3390/nu5093399

8. Yang H, Xun P, He K. Fish and fish oil intake in relation to risk of asthma: a systematic review and meta-analysis. PLoS One (2013) 8:e80048. doi:10.1371/ journal.pone.0080048 future investigations should also pay attention to the evidence of intervention studies on fatty acid supplementation in pregnancy, during lactation, or during infancy. Obviously, timing of exposure is an important issue. Moreover, for maternal supplementation, maternal uptake and secretion into breast milk can lead to variation across mothers. Also, child uptake of fatty acids may differ by a various factors associated with infant feeding such as timing, frequency, and maternal diet. Therefore, another approach to exposure assessment may be to directly measure fatty acid levels in infant serum. However, this may be limited due to practical and ethical reasons in small infants but could be easier and potentially informative in animal model settings.

Finally, early infancy is a particularly important period for development of the immune system and of the gut microbiome which may potentially be associated with childhood atopic outcomes. Therefore, we agree with the current review and believe future studies should add to ours by analyzing fatty acids and other constituents in colostrum which may be differentially associated with disease outcomes.

To move forward, we suggest (i) building on the existing systematic reviews, (ii) employing the centered log ratio transformation to overcome spurious correlation, (iii) considering alternative ways of grouping fatty acids, (iv) reducing selection bias by sampling infant formula, (v) further investigating other forms of exposure assessment (upstream as maternal fatty acid supplementation, downstream, or as part of animal models), and (vi) bearing in mind timing of exposure.

\section{AUTHOR CONTRIBUTIONS}

Both CL and JG have conceived and written this commentary.

9. Muley P, Shah M, Muley A. Omega-3 fatty acids supplementation in children to prevent asthma: is it worthy?-a systematic review and meta-analysis. J Allergy (2015) 2015:312052. doi:10.1155/2015/312052

10. Gunaratne AW, Makrides M, Collins CT. Maternal prenatal and/or postnatal n-3 long chain polyunsaturated fatty acids (LCPUFA) supplementation for preventing allergies in early childhood. Cochrane Database Syst Rev (2015) 7:CD010085. doi:10.1002/14651858.CD010085.pub2

11. Logan CA, Brandt S, Wabitsch M, Brenner H, Wiens F, Stahl B, et al. New approach shows no association between maternal milk fatty acid composition and childhood wheeze or asthma. Allergy (2017) 72:1374-83. doi:10.1111/all.13161

12. Aitchison J, Egozcue JJ. Compositional data analysis: where are we and where should we be heading? Math Geol (2005) 37:829-50. doi:10.1007/s11004005-7383-7

13. Gloor GB, Wu JR, Pawlowsky-Glahn V, Egozcue JJ. It's all relative: analyzing microbiome data as compositions. Ann Epidemiol (2016) 26:322-9. doi:10.1016/j.annepidem.2016.03.003

14. Conte G, Serra A, Cremonesi P, Chessa S, Castiglioni B, Cappucci A, et al. Investigating mutual relationship among milk fatty acids by multivariate factor analysis in dairy cows. Livest Sci (2016) 188:124-32. doi:10.1016/j.livsci. 2016.04.018

15. Rocquelin G, Tapsoba S, Dop MC, Mbemba F, Traissac P, Martin-Prével Y. Lipid content and essential fatty acid (EFA) composition of mature Congolese breast milk are influenced by mothers' nutritional status: impact on infants' EFA supply. Eur J Clin Nutr (1998) 52:164-71. doi:10.1038/sj.ejcn.1600529

16. Logan C, Zittel T, Striebel S, Reister F, Brenner H, Rothenbacher D, et al. Changing societal and lifestyle factors and breastfeeding patterns over time. Pediatrics (2016) 137:e20154473. doi:10.1542/peds.2015-4473

17. Szabó E, Boehm G, Beermann C, Weyermann M, Brenner H, Rothenbacher D, et al. Fatty acid profile comparisons in human milk sampled from the 
same mothers at the sixth week and the sixth month of lactation. J Pediatr Gastroenterol Nutr (2010) 50:316-20. doi:10.1097/MPG.0b013e3181a9f944

Conflict of Interest Statement: The authors declare that the research was conducted in the absence of any commercial or financial relationships that could be construed as a potential conflict of interest.
Copyright (๑) 2018 Logan and Genuneit. This is an open-access article distributed under the terms of the Creative Commons Attribution License (CC BY). The use, distribution or reproduction in other forums is permitted, provided the original author(s) and the copyright owner are credited and that the original publication in this journal is cited, in accordance with accepted academic practice. No use, distribution or reproduction is permitted which does not comply with these terms. 